\title{
ЭФФЕКТИВНОСТЬ МЕР ГОСПОДДЕРЖКИ СТАНКОСТРОЕНИЯ
}

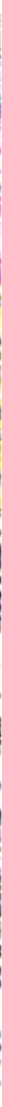

Российские производители станкостроительной продукции работают в жестких конкурентных условиях. Им приходится вести борьбу за отечественный рынок с ведущими мировыми производителями, обладающими огромным опытом, мощной производственной базой и значительными финансовыми ресурсами для маркетинга и проведения НИОКР. Рядом Постановлений Правительства РФ, в частности № 719 от 17 июля 2015 года и № 239 от 7 марта 2019 года, предусмотрены меры государственной поддержки отечественных предприятий. Насколько эффективны предложенные инструменты? Какое воздействие они оказывают на общее состояние и динамику отрасли, на деятельность российских производителей станкоинструментальной продукции? Какова роль господдержки в развитии компаний, увеличении количества перспективных разработок и расширении номенклатуры отечественных комплектующих? Эти и другие актуальные вопросы редакция адресует ведущим отраслевым экспертам. Их ответы мы будем регулярно публиковать на страницах журнала «СТАНКОИНСТРУМЕНТ» в новой рубрике «Мнения экспертного сообщества». 


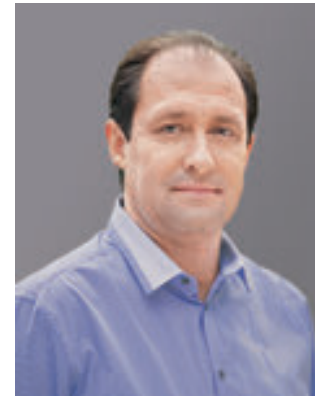

\section{Олег Иванович БОЧКАРЁВ}

заместитель председателя коллегии Военно-промышленной комиссии Российской Федерации

В настоящее время много дискуссий посвящено необходимости преодоления упадка российской станкостроительной отрасли. Один из основных вопросов заключается в том, как нам организовать начатую 15 лет назад работу по восстановлению отечественного станкостроения (производства средств производства).

Более 25 лет назад, когда открылись рынки, наша промышленность «подсела» на станки иностранного производства. Попытки повернуть ситуацию в сторону российского производителя оказались сложной задачей.

Смысл дискуссии о том, выходит российское станкостроение из кризиса или нет, - это лишь отражение философского вопроса о частично заполненном водой стакане. Пессимисты утверждают, что стакан наполовину пуст, а оптимисты, естественно, что он наполовину полон.

Меры, реализованные государством и бизнесом за последние 15 лет, обеспечили положительную динамику, что подтверждается аналитическими данными, которые предоставляет Ассоциация «Станкоинструмент». При этом достижение более высокого уровня качества, надежности и эффективности работы предприятий станкостроительной отрасли по-прежнему на повестке дня. Пока удельный вес приобретаемого российского оборудования оставляет желать лучшего, поскольку составляет всего $10 \%$ от импорта.

Если рассматривать обсуждаемый вопрос с точки зрения эффективности мер господдержки, то для восстановления рынка сделано многое. В частности, действует механизм, согласно которому для приобретения станков и оборудования за государственные деньги требуется получить разрешение Минпромторга России. Покупка иностранного оборудования возможна только при наличии подтверждения, что продукция подобного уровня в нашей стране не производится. Безусловно, этот вопрос - предмет внимательного изучения, поскольку заказчики станков в силу разных субъективных и объективных причин стараются обосновать покупку иностранного оборудования. Привыкли! Подобная точка зрения сформировалась не на пустом месте. Обоснованно критикуются и качество российских станков, и сроки выполнения работ, есть пре- тензии и к некоторым техническим параметрам продукции.

Я всегда придерживался мнения о том, что, начав производство собственного оборудования и пройдя достаточно большой путь, мы в любом случае получим нужный результат. Следует понимать, если мы только сегодня открыли производство, то не бывает так, чтобы выпускаемая продукция сразу соответствовала передовому техническому уровню.

Накопленные в станкостроении опыт и ресурсы - это очень важно. Нельзя останавливаться, и тогда через несколько лет производимые в России станки будут соответствовать мировому уровню.

Не менее важный вопрос - производство отечественных комплектующих. Понятно, что в силу различных причин, мы не можем позволить себе производство всех комплектующих для российских станков. Станкостроительные заводы всегда были «финишерами» в производственной цепочке, отдельные комплектующие приобретались у других производителей.

Электроника, системы ЧПУ, точная механика (редукторы, шпиндели, шарико-винтовые пары) не всегда находятся внутри периметра станкостроительной отрасли. Оптимизация производства отдельных комплектующих - задача сегодняшнего дня.

Отечественные предприятия, получившие статус российского производителя, заимствуют много импортных узлов и агрегатов, что разрешено в соответствии с Постановлением Правительства № 719. Так принято во всем мире. Международная кооперация - основной принцип выпуска станков в любой стране, предприятия которой являются их производителями.

В отрасли не обходится, конечно, без определенных ограничений, связанных, в частности, с санкционной политикой. Поставки отдельных комплектующих для сверхточных станков являются проблемой, но наши предприятия научились с ней справляться. Пока освоение производства комплектующих изделий в Российской Федерации идет не такими быстрыми темпами, как хотелось бы. Но я остаюсь оптимистом и полагаю, что в обозримом будущем мы будем в большем объеме выпускать собственные комплектующие. К тому же в рамках диверсификации оборонно-промышленного комплекса стоит задача освоения гражданской продукции.

В реализации этих проектов принимают участие и госкорпорации. В качестве примера можно привести входящий в ГК «Ростех» Ковровский электромеханический завод или ФГУП «Приборостроительный завод» (ПСЗ) в г. Трёхгорный, на котором ГК «Росатом» планирует локализовать производство. 
Частные предприятия показывают хорошие результаты, например Группа компаний «СТАН», в структуру акционеров которой вошел «Ростех». Благодаря взаимодействию с одной из самых сильных в административном, финансовом и экономическом плане госкорпораций Группа «СТАН» значительно расширила свои возможности.

Еще одна тема для дискуссий в отраслевом сообществе - локализация зарубежных производств. Узлы и агрегаты, которые пока не производятся в России, дают самую большую добавленную стоимость. Неэффективно продавать станок, когда лишь $30 \%$ его стоимости остается в стране. Продвигая отечественную продукцию, мы стремимся к решению этой проблемы. Поэтому роль локализации трудно переоценить. При этом нужно учитывать разумные границы и не пытаться производить у себя все, вплоть до последнего болтика.

Вице-премьер Юрий Иванович Борисов инициировал создание системы квотирования закупок в интересах отечественного производства. Мы работаем над повышением уровня защиты российских производителей от иностранной продукции, чтобы они могли наращивать объем и номенклатуру выпускаемых изделий. Это расширит их экономические возможности, позволит успешно конкурировать на современном рынке.

В настоящее время основные законодательные инициативы направлены на усиление позиций российских предприятий на внутреннем рынке. Способов достижения поставленной цели немало - квоты, защита внутреннего рынка от иностранной продукции или реализация иных мер поддержки отечественного производителя: субсидии, дополнительный процент при подведении итогов конкурсов, когда преференции получает отечественная продукция. Подобные меры, безусловно, нужны, но при этом и производители должны соответствовать современному уровню техники и технологий, качества, надежности и сервиса, которые сегодня обеспечивают иностранные компании.

Что касается постановлений правительства, предусматривающих меры поддержки отечественного производителя станкоинструментальной продукции, то сегодня действуют более 100 документов. При этом необходимо постоянно анализировать, как они применяются, каков результат. Кроме того, в силу различных причин специалисты могут не знать об этих мерах, хотя все они доступны: документы находятся в открытом доступе на информационном ресурсе Минпромторга России - ГИСП.

Стороны, заинтересованные в применении методов государственной поддержки, всегда могут с ними ознакомиться, разобраться в их сути с помощью представителей Минпромторга России, обсудить проблемы. Вам подскажут, объяснят, сориентируют. Специалисты министерства глубоко погружены в отраслевую проблематику и правовые детали господдержки отечественного производителя.

Представители промышленных предприятий не всегда обладают этими знаниями, иногда идут по ошибочному пути или стучатся в уже открытые двери. Отсутствие информации, плохая коммуникация снижают эффект мер государственной поддержки, которые Минпромторг России реализует и на которые выделяются бюджетные деньги. Известны случаи, когда Минпромторг России вынужден возвращать деньги в бюджет, потому что никто из промышленников не воспользовался предлагаемой методикой. Поэтому подчеркну важность коммуникации.

Еще одна, пока не реализованная, но обсуждаемая мера продиктована тем, что предприятиям станкостроения не хватает оборотного капитала. Действующие способы поддержки связаны с покупкой станков, созданием программного обеспечения, локализацией производства. Все, что относится к основным фондам - «железу» - работает. Но коллеги, которые непосредственно занимаются бизнесом, четко формулируют проблему нехватки оборотного капитала. Можно взять кредит в банке, однако высокий процент негативно скажется на экономике предприятия.

Проблема актуальна не только для станкостроения. У предприятий есть хорошие контракты - и объемы большие, и с финансовой точки зрения выгодные, но нужно закупить сырье, материалы, комплектующие, внести авансы субподрядчикам, платить зарплату. А технологический срок изготовления станка - не один день. На выпуск сложного оборудования для авиации, судостроения может потребоваться полтора-два года. Где руководителям предприятий брать на это деньги? Промышленники остро ставят вопрос, правительство и Минпромторг России об этом знают. Как эксперт, я выступаю за то, чтобы оказать поддержку нашим предприятиям в вопросе пополнения оборотного капитала для текущей производственно-хозяйственной деятельности.

Если говорить о техническом уровне российского станкостроения, то техника и технологии развиваются, появляются новые решения, которые каждый год демонстрируются на выставке «Металлообработка» в Москве. Например, «Туламашзавод» заявил о готовности выпускать высокоточные станки. Когда на одной из выставок, 
мы обсуждали такую возможность, не обошлось без доли скептицизма - едва ли предприятие сможет обеспечить заявленные технические характеристики, соответствующие сверхточным станкам. Но в течение года на «Туламашзаводе» создали такие станки, были проведены испытания, изготовлены детали. Как показали замеры, продукция соответствует требованиям заказчика. Это свидетельство того, что новый уровень развития техники доступен нашим оборонным предприятиям.

В данном направлении нужно двигаться дальше, несмотря на отсутствие системных институ- тов развития станкостроения. Насколько мне известно, 4 марта на очередном заседании Ассоциации «Станкоинструмент», которое состоится на базе АО «ВНИИИНСТРУМЕНТ», мы вместе обсудим вопросы и проблемы дальнейшего развития отрасли.

Если вернуться к началу нашего разговора и вспомнить, что всерьез проблематикой станкостроения мы занялись 15 лет назад, то мне, как эксперту, есть с чем сравнивать. Только тому, кто занимается проблемой относительно недавно, может показаться, что мы топчемся на месте. Не стоит верить таким экспертам. Мы движемся вперед!

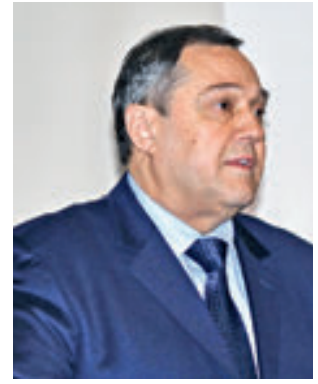

Георгий Васильевич САМОдУРОВ президент Российской Ассоциации производителей станкоинструментальной продукции «Станкоинструмент»

Станкоинструментальная отрасль, обеспечивающая технологическую безопасность страны, функционирует в составе промышленного комплекса страны и во многом зависит от итогов ее деятельности. Исходя из этого, пути преодоления трудного состояния должны носить как общегосударственный, так и отраслевой характер. Меры общегосударственные должны быть направлены на решение трех ключевых задач:

1. Разумная кредитно-финансовая политика всех финансовых институтов под непосредственным управлением центрального банка. ЦБ должен отвечать за экономический рост в стране, а не за удержание инфляции в размере, не превышающем 4\% в год.

2. Налоговая политика должна, помимо фискальной, играть стимулирующую роль. На протяжении трех последних лет рост собираемости налогов составляет по прибыли от 17 до 25\%, НДС - от 11 до 16\%; имущественный и земельные налоги - от 9 до 12\% Рост ВВП в 2019 году составил при этом 101,7\%. Количество предприятий в 2019 году в промышленности сократилось на 9\%. В 2018 году закрылось 41 тыс. предприятий в обрабатывающей промышленности. Резонный вопрос - кто для кого существует? Где стимулирующая роль налогового сектора?

3. Необходима разумная протекционистская политика государства по отношению к отечественным производителям на всех уровнях, как это имеет место быть во всех развитых, в технологическом отношении, странах.
Bсе это в конечном итоге должно приводить к росту ВВП страны, повышению благосостояния и росту доходов населения и обеспечивать решение национальных и стратегических задач России на период 2019-2024 годов.

\section{Национальные цели и стратегические задачи России, 2019-2024 годы}

Указ Президента РФ от 7 мая 2018 года (с учетом национальных проектов):

$\rightarrow$ рост ВВП России на душу населения в 1,5 раза; $\rightarrow$ вхождение в пять крупнейших экономик мира, обеспечение темпов экономического роста выше мировых при инфляции ниже 4\%;

$\rightarrow$ повышение до 25\% ВВП инвестиций в основной капитал;

$\rightarrow$ рост производительности труда не ниже 5\% в год;

$\rightarrow$ увеличение несырьевого экспорта до 250 млрд долл. США в год: машиностроения - до 50 млрд долл. США, агропрома - до 45 млрд долл. США, услуг - до 100 млрд долл. США в год;

$\rightarrow$ увеличение численности занятых в сфере МСП до 25 млн чел.;

$\rightarrow$ увеличение строительства жилья до 120 млн кв. м в год;

$\rightarrow$ снижение в два раза уровня бедности в Российской Федерации.

\section{Замкнутый круг отстающего роста экономики России}

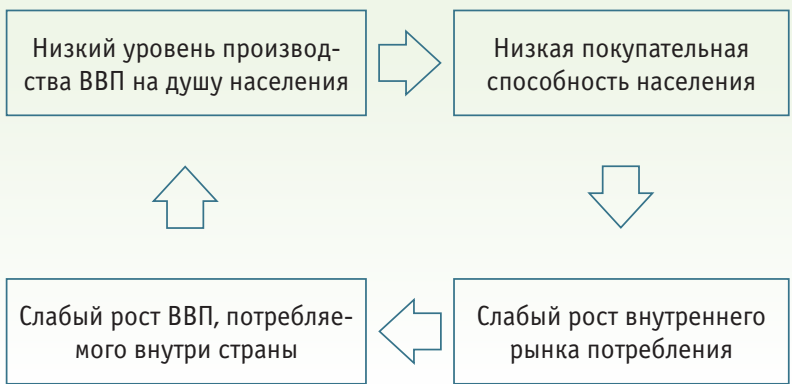


Если говорить о решении проблем отрасли, то их можно представить в виде таблицы:

\begin{tabular}{|c|c|}
\hline $\begin{array}{l}\text { Проблемы, связанные с } \\
\text { производством }\end{array}$ & $\begin{array}{l}\text { Проблемы научно-технической } \\
\text { деятельности и инновации }\end{array}$ \\
\hline $\begin{array}{l}\text { Недостаток собствен- } \\
\text { ных оборотных средств } \\
\text { и инвестиционных } \\
\text { ресурсов у большинства } \\
\text { предприятий отрасли; } \\
\text { высокий уровень износа } \\
\text { основных фондов пред- } \\
\text { приятия; } \\
\text { высокая импортозависи- } \\
\text { мость по комплектующим } \\
\text { изделиям и материалам; } \\
\text { жесткие условия и цено- } \\
\text { вая зависимость по } \\
\text { поставкам энергоресур- } \\
\text { сов }\end{array}$ & $\begin{array}{l}\text { - Недостаток собственных } \\
\text { средств предприятия на } \\
\text { НИокР; } \\
\text { - недостаточность отраслевой } \\
\text { научно-технической полити- } \\
\text { ки; } \\
\text { - практически полное отсут- } \\
\text { ствие профильных научно- } \\
\text { исследовательских отрасле- } \\
\text { вых институтов } \\
\text { и организаций; } \\
\text { - слабая связь с фундамен- } \\
\text { тальной наукой }\end{array}$ \\
\hline
\end{tabular}

По каждому из этих направлений у Ассоциации есть видение и предложения по их решению. Это и предложения по формированию комплекса мер по нормативно-правовому регулированию, внесению поправок и корректировок в существующие постановления и распоряжения, и меры самих предприятий.

Важный вопрос - организация производства комплектующих изделий для выпуска металлообрабатывающего оборудования в стране. В течение всего 2019 года Ассоциация очень тесно взаимодействовала с предприятиями, различными государственными корпорациями. Результатом этой работы стали две аналитические записки по состоянию и предложению организации выпуска комплектных систем ЧПУ и других наиболее важных и необходимых комплектующих изделий. Мы убеждены, что проведенная аналитическая работа, тесное взаимодействие с Агентством по технологическому развитию России, контакты с рядом крупных производителей этих изделий в мире создали определенную положительную ситуацию в этом направлении. В рамках программ конверсии появился повышенный интерес к номенклатуре изделий со стороны предприятий Росатома, Ростеха. В Фонде развития промышленности существует стандарт, который финансово помогает решить эту проблему, есть и другие источники.

Позиция России по итогам 2019 года:

$\rightarrow$ ВВП номинал - 109,4 трлн руб., рост 4,9\% (реал. 1,3\%): 11 место в мире;

$\rightarrow$ ВВП по ППС - 4,2 трлн долл. США (оценка), рост 2,5\%: 6 место в мире;

$\rightarrow$ ВВП номинал на душу -756 тыс. руб. $=12,2$ тыс. долл. США (62 (-2) место в мире);

$\rightarrow$ ВВП по ППС на душу населения - 28,8 тыс. долл. США (50 (-1) место в мире);
Проблемы, связанные со сбытом на внутреннем рынке

- Недостаток системы госзакупок, связанный с нестыковками законодательных актов (Федеральные законы № 223 и 44);

- отсутствие ответственности потребителей продукции за невыполнение норм ПП № 9 от 14 января 2017 года;

- неэффективная роль выполнения ПП № 719 при получении статуса российского производителя;

- низкий уровень информированности конечных потребителей о современной продукции станкоинструментальной отрасли
Проблемы кадрового обеспечения

- Дефицит квалифицированных кадров;

- недостаток профессиональных и образовательных стандартов;

- отсутствие государственной системы подготовки кадров рабочих профессий и специалистов среднего звена

$\rightarrow$ производительность труда - 26 долл./ч (EC 56 долл./ч, США - 67 долл./ч);

$\rightarrow$ инвестиции в основной капитал - 18,5 трлн руб. (оценка), 16,9\% ВВП;

$\rightarrow$ несырьевой экспорт - 135 млрд долл. США (оценка) из 420 млрд долл. США всего экспорта;

$\rightarrow$ численность занятых в сфере МСП - 15,4 млн чел., падение 3,8\% (1,7 млн - средние, 6,2 млн малые, 7,5 млн - микропредприятия);

$\rightarrow$ жилищное строительство - 75 млн кв. м (оценка);

$\rightarrow$ количество бедных (доход $<$ прожит. $\min )=>$ 20 млн чел. (+5\%).

\section{Источники инвестиций в основной капитал в России}

Всего инвестиций в 2019 году - около 18,5 трлн руб. (оценка):

$\rightarrow$ собственные средства - 52\%;

$\rightarrow$ привлеченные средства $-48 \%$, в том числе:

$\checkmark$ государственные средства - 16,5\%;

$\checkmark$ кредиты банков - 11,2\% (из них иностранных $-5,4 \%)$;

$\checkmark$ корпоративные займы - 5,4\%;

$\checkmark$ долевое участие в строительстве - 3,3\% (из них население - 2,8\%);

$\checkmark$ прямые иностранные инвестиции - 0,8\%;

$\checkmark$ фондовый рынок - 0,3\%;

$\checkmark$ иные - 10,5\%.

Важную роль играют меры государственной поддержки в развитии предприятий, как нашей отрасли, так и смежных отраслей. От того, как выстроен механизм инвестиционной деятельности, во многом зависят итоги работы станкостроителей. Сегодня действует около 85 различных мер государственной поддержки. В 2018 году было 
выделено 288 млрд руб. на поддержку предприятий. Для 290 тыс. предприятий, функционирующих в обрабатывающей промышленности, это составляет менее $1 \%$ от их оборота. Этого совер- шенно недостаточно, так как большинство предприятий находится на грани выживания. И это несмотря на то, что есть необходимые источники для этого.

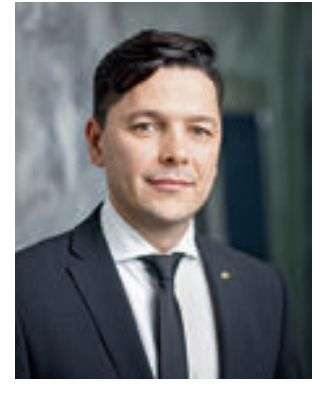

Кирилл Владимирович ПЕТРОВ акционер Липецкого станкостроительного предприятия

Вопрос эффективности господдержки с точки зрения бизнеса в России для таких высокотехнологичных производств, как станкостроение, достаточно спорный. А при условии локализации производства, согласно правил Постановления Правительства РФ № 719 от 17 июля 2015 года «О критериях отнесения промышленной продукции к промышленной продукции, не имеющей аналогов, произведенных в Российской Федерации», я могу точно утверждать, что экономически данный бизнес становится уже неприбыльным. Прежде всего это связано с тем, что доля добавленной стоимости, которая локализуется в рамках проектов таких производств, будет невелика. Также, при существующем в настоящее время состоянии производства изделий общестанкостроительного применения, обеспечение нормативного уровня локализации в 50\% и более зачастую еще до начала производства заранее предопределяет высокую стоимость станка по отношению к зарубежным аналогам (к стоимости изделий надо добавить стоимость доставки, НДС, пошлины и т.п.). Технический уровень станков также может отличаться не в лучшую сторону, так как часто применяются общестанкостроительные изделия более низкого технического уровня и стоимости (с целью оптимизации себестоимости) и, соответственно, недостаточного качества.

Разумеется, в наукоемкой станкостроительной отрасли промышленности, помимо текущей коммерческой эффективности, следует учитывать и стратегические соображения технологической независимости и безопасности страны. С этой точки зрения локализация производства станкостроительной продукции и высокотехнологичных компонент, особенно для критически значимых деталей, узлов и механизмов станков - важное направление ликвидации технологического отставания, сложившегося в станкоинструментальной отрасли промышленности в России. В связи с этим реализация на практике Постановления Правительства РФ № 239 от 7 марта 2019 года «Об установлении запрета на допуск отдельных видов товаров станкоинструментальной промышленности...» требует решения задач локализации или организации станкоинструментальной продукции с наибольшей эффективностью, тем более критически значимой номенкла- туры. Для этого Минпромторгом России создается реестр российской станкоинструментальной продукции, основанием для включения в который служит Постановление Правительства РФ № 719 от 17 июля 2015 года «О критериях отнесения промышленной продукции к промышленной продукции, не имеющей аналогов, произведенных в Российской Федерации». Данные механизмы позволяют конкурировать на отечественном рынке с ведущими мировыми производителями, обладающими огромным опытом, мощной производственной базой и значительными финансовыми ресурсами для проведения НИОКР.

Однако, применение данных механизмов без учета технологических особенностей станкостроительного производства с большой долей уверенности приведет к неконкурентоспособности локализованных в стране производств в долгосрочной перспективе. Можно также сказать, что интеграция в мировую торговлю будет неэффективной, как с технической, так и с коммерческой точки зрения. В связи с этим, отечественные станкостроители не смогут конкурировать на мировых рынках без дополнительной существенной поддержки со стороны государства. Тем более, что протекционизм очень широко применяется на мировом рынке со стороны стран - ведущих производителей станков, таких как Япония, Южная Корея, Китай, Германия и т. д. Это связано с тем, что станки являются важным конкурентным преимуществом для любой национальной промышленности.

К таким механизмам поддержки можно отнести следующее:

1. Корректировку таможенных пошлин либо в сторону увеличения пошлин на станки, которые сейчас находятся на уровне от 0\% (например, на круглошлифовальные станки с ЧПУ) до 10\%, либо в сторону снижения таможенных пошлин на комплектующие и станочные компоненты, которые не производятся в нашей стране. Без устранения этого перекоса станок, произведенный в России, всегда будет иметь значительно большую себестоимость.

2. Необходимо освободить от налога инвестиции, направленные на модернизацию производств и создание новых производств на всей территории РФ.

3. Для поддержки отрасли станкостроения необходимо снизить НДС на отечественные станки до $10 \%$, а возможно, на какой-то период времени и до $0 \%$ - это приведет к высвобождению и наращиванию оборотного капитала у производителей, а также безбарьерный возврат НДС 
от налоговых органов, что также существенно будет способствовать развитию экспорта.

4. Необходимо стимулировать покупателей отечественных станков при помощи субсидий и возврата части стоимости станка (например, 30\%) при его прямой покупке либо 10-15\% - при использовании лизинговых компаний. Такие успешные меры поддержки правительство уже применяет не первый год в автомобилестроении и в сельхозмашиностроении. Результаты применения этого механизма привели к желаемым результатам.

5. Необходимо создать реестр отечественных производителей станков (например, на базе данных Ассоциации «Станкоинструмент») и обеспечить бесплатный доступ к новейшим разработкам, осуществляемым ведущими институтами и разработчиками станкоинструментальной продукции с целью внедрения этих разработок в производство.

6. Необходимо обеспечивать $100 \%$-ное финансирование НИОКР со стороны государства в области станкостроения. При этом надо предусматривать, что КПД НИОКР никогда не может быть 100\%. Зачастую, в нашем государстве если финансирование работ или услуг не привело к желаемому результату, то это всегда повод вмешательства в данную сферу со стороны силовых структур, что автоматически ведет к ее разрушению.

7. Создать реестр экспортеров станков и возвращать им 50\% себестоимости станков при помощи субсидий. В этом случае возможно задействовать торговые представительства России в других странах.

8. Экспортерам дать возможность пользоваться инфраструктурой торговых представительств (например, офисными помещениями, конференцзалами, переводчиками, транспортом, базами данных о состоянии торговли и промышленности в других странах).

Необходимо также учесть, что для создания новых, более прогрессивных и инновационных станков необходимо не только обеспечить структурные (жесткость, пространство обработки и т.п.) и функциональные возможности (функции формообразования, управления, контроля и т.п.), основанные на новых принципах проектирования станка, но и быстро внедрять передовые технологии, материалы и компоненты, разрабатывать новые технологии в области станкостроения. Для внедрения этих технологических особенностей в производство необходимы постоянные огромные вложения в производство и НИОКР, которые в нашей стране при существующих особенностях налоговой системы, таможенных правил и пошлин, а также сложившегося рынка потребления никогда не окупятся. Также, для поддержания конкурентоспособности станкостроители, в свою очередь, существенно изменили структуры производства данного вида оборудования. Произошла трансформация станкостроительных заводов из предприятий полного технологического цикла в относительно компактные, тяготеющие к сборочному производству предприятия с подразделениями финишной мехобработки и обработки критически значимых и оригинальных деталей и узлов. Изготовление наукоемких комплектующих общестанкостроительного применения сосредоточилось среди достаточно ограниченного числа крупных производителей, способных обеспечить их серийное производство и приемлемую стоимость.

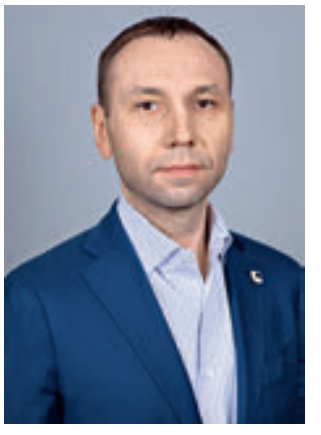

Алексей Павлович ПодоРогин генеральный директор АО «ДИОМАШ-ИНЖИНИРИНГ»

\section{Два пути развития отече-} ственного станкостроения.

Оба постановления преследуют актуальную для нашей страны стратегическую цель возрождение отечественного производства станков и инструментов. На мой взгляд, развивать станкостроение в России можно несколькими путями.

Первый, по аналогии с тактикой мировых автопроизводителей, - это открытие локального производства в Российской Федерации, но с обязательным участием в проекте местного партнера. Стимулом для иностранных предприятий в данном случае служит возможность расширения сбыта на нашем рынке, а у отечественных компаний сохра- няются шансы перенять технологии и развиваться в тренде мирового станкостроения. Подобные примеры уже есть и постепенно реализуются. Но им нужна поддержка государства в виде снижения бюрократических барьеров при оформлении подтверждения производства на территории Российской Федерации. При этом важны настрой ответственных лиц в профильных ведомствах, готовых к открытому и беспрепятственному диалогу с представителями станкостроительных компаний, помощь в осмыслении требований законодательства и самое главное - оперативные действия с соблюдением установленных сроков. Кроме того, четкие требования законодательства должны быть стабильными, неизменными продолжительное время, чтобы бизнес мог планировать работу в долгосрочной перспективе.

Актуальная проблема в сфере производства станков, соблюдения требований Постановления Правительства РФ № 719 от 17 июля 2015 года связана с компонентной базой. 
Необходимо развивать производство комплектующих в нашей стране (сегодня оно фактически отсутствует), ведь их наличие в конечном изделии - важнейшее условие признания подтверждения производства на территории Российской Федерации. В решение этой задачи необходимо вкладывать большие усилия.

Второй путь возрождения станкоинструментальной промышленности предусматривает использование опыта СССР и практики современных предприятий Тайваня. Прежде всего речь идет о создании государственных специализированных институтов для выполнения НИОКР, результатами которых смогут воспользоваться все заинтересованные станкостроители. В таком случае каждому из них не придется содержать собственное конструкторское бюро - необходимые работы будут выполняться централизованно в одном месте. Как известно, в станках много универсальных компонентов, поэтому данный вариант будет оправдан с экономической точки зрения. Такой подход поможет развитию не только крупных серийных производителей, но и небольших компаний, которые могут стать

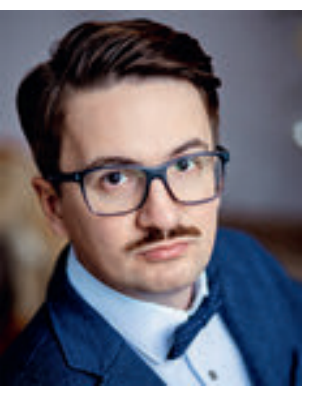

Василий Иванович КУЗНЕЦОВ исполнительный директор 000 «НПК «Дельта-Тест»

Безусловно, оба обозначенных документа являются крайне важными, нужными как для отдельных отечественных предприятий, занимающихся разработкой и выпуском станкоинструментальной продукции, так и для всей отрасли машиностроения в целом. Сложные глобальные конкурентные условия 21-го века, история развала отрасли в 90-е годы и тот факт, что в любой стране мира станкостроение очень тесно связано с сектором ОПК, подтверждают необходимость решения проблемы на самом высоком государственном уровне. И лично мне очень хочется надеяться, что принятие данных инициатив можно рассматривать как отправную точку начала нового тренда: постепенного восстановления этих критических отраслей промышленности в России.

Уверен, действовать в данном направлении следует, с одной стороны, «быстро и широко», чтобы эффект от принимаемых мер был реально ощутимым. Но, с другой стороны, очень важно быть «аккуратным», не создать излишних помех, бюрократических барьеров для всех существующих отечественных участников рынка. Нельзя слишком сильно «зарегулировать систему».

Так, сегодняшняя задача освоения госкорпорациями гражданской продукции высоко коррелирует с обсуждаемыми мерами. В этой связи, Постановления № 719 и более универсальными и при этом достаточно гибкими, способными подстраиваться под индивидуальные требования клиента.

Кроме того, для ознакомления с возможностями отечественного станкостроения важно при поддержке Министерства промышленности и торговли проводить семинары с участием представителей подведомственных промышленных предприятий.

Безусловно, Постановления Правительства РФ № 719 от 17 июля 2015 года «О подтверждении производства промышленной продукции на территории Российской Федерации» (в редакции, действующей с 1 января 2020 года) и № 239 от 7 марта 2019 года «Об установлении запрета на допуск отдельных видов товаров станкоинструментальной промышленности, происходящих из иностранных государств, для целей осуществления закупок для нужд обороны страны и безопасности государства» следует рассматривать как меры, содействующие возрождению отечественных производителей станкоинструментальной продукции в среднесрочной перспективе.

239 являются серьезным «подспорьем» в рамках такой конверсии. Но ни в коем случае нельзя «забывать» 0 частных компаниях малого и среднего бизнеса, многие из которых пережили сложнейшие десятилетия и, несмотря ни на что, сумели накопить существенный опыт, создавать инновационную станкостроительную продукцию в жестких условиях конкуренции с мировыми производителями на практически незащищенном отечественном рынке. С моей точки зрения, именно такие предприятия могут стать драйверами роста и будут одновременно являться гарантией наличия внутренней конкуренции, без которой невозможно достижение конечной цели по созданию продукции мирового уровня качества и технологической оснащенности.

Таким образом, важнейшую роль играет широкое обсуждение вопросов корректировки пунктов Постановления № 719 о критериях и правилах отнесения продукции к «произведенной в Российской Федерации». Привлечение к вопросу отраслевых ассоциаций, университетов и научных институтов. Анализ реальных кейсов применения данного постановления, возникающих сложностей и неоднозначной трактовки отдельных пунктов. Отмечу, что начиная с 2017 года по сегодняшний день специалисты ООО «НПК «Дельта-Тест» также принимают активное участие в рабочих группах при Минпромторге России, Ассоциации «Станкоинструмент», ведущих доработку разделов Постановления Правительства РФ № 719 с привлечением производителей станкоинструментальной продукции. В целом все произошедшие за этот период изменения носят положительный характер и должны стать защитой действительных отечественных разработчиков современных станков. Будем надеяться, что практика подтвердит вышесказанное. 